\title{
Yapay Sinir Ağı (YSA) Kullanarak Farklı Kaynaklardan Türkiye'de Elektrik Enerjisi Üretim Potansiyelinin Tahmini
}

\section{Estimation of Electricity Production Potential in Turkey from Different Sources Using Artificial Neural Network (ANN)}

\author{
Harun IŞIK ${ }^{* 1}$ iD , Mustafa ŞEKER ${ }^{2}$ \\ ${ }^{1}$ Elektrik-Elektronik Mühendisliği Bölümü, Sivas Cumhuriyet Üniversitesi, Sivas, Türkiye \\ ${ }^{2}$ Hafik Kamer Örnek Meslek Yüksek Okulu, Ulaştırma Hizmetleri Bölümü, Sivas Cumhuriyet Üniversitesi, Sivas, \\ Türkiye
}

(20209233011@cumhuriyet.edu.tr, mustafaseker@cumhuriyet.edu.tr)

Received: Sep.4, 2021

Accepted: Sep.16, 2021

Published: Oct.20, 2021

\begin{abstract}
Özetçe - Dünya üzerinde elektrik enerjisi talebi her geçen gün artmaktadır. Atran talebi karşılamak ve gerçekleştirilmesi planlanacak olan üretim yatırımlarının ekonomik değerinin belirlenmesi açısından uzun dönem elektrik üretim tahminlerinin yapılması büyük önem arzetmektedir. Bu çalışmada, Türkiye'nin 1985-2019 yılları arasındaki kurulu güç kapasitesi, bürüt elektrik üretimi, net elektrik tüketimi, ithalat, ihracat ve nüfus gibi enerji göstergeleri kullanılarak enerji üretim tahmini için yapay sinir ağı (YSA) tabanlı tahmin metodolojisi sunulmuştur ve petrol, gaz, kömür ve diğer enerji (yenilenebilir enerji) kaynaklarından elektrik üretim tahmini gerçekleştirilmiştir. Tahmin sonuçları istatistiksel olarak değerlendirilmiştir ve sunulan yaklaşımın doğruluğu test edilmiştir. Elde edilen sonuçlar enerji indikatörlerine bağlı olarak YSA yardımıyla enerji üretim tahminin yüksek doğruluk ile kullanılabileceğini göstermektedir.
\end{abstract}

Anahtar Kelimeler: Yapay sinir ă̆ı (YSA), Enerji tahmini, Elektrik enerji üretimi.

Abstract - The demand for electrical energy in the world is increasing day by day. It is of great importance to make long-term electricity production forecasts in terms of meeting the increasing demand and determining the economic value of the generation investments that will be planned to be realized. In this study, an artificial neural network (ANN) based estimation methodology is presented for energy production forecasting using energy indicators such as Turkey's installed power capacity, gross electricity production, net electricity consumption, imports, exports and population between the years 1985-2019. Electricity production estimation was made from oil, gas, coal and other energy (renewable energy) sources. The estimation results were statistically evaluated and the accuracy of the presented approach was tested the results obtained show that energy production estimation can be used with high accuracy with the help of ANN based on energy indicators.

Keywords: Artificial Neural Network (ANN),Energy Forecasting,Electric Power Generation. 


\section{GİRIŞ}

Gelişen teknoloji, sanayileşme ve hızlı nüfus artışına bağlı olarak tüm dünyada olduğu gibi Türkiye'de de elektrik enerjisine duyulan gereksinim her geçen gün artış göstermektedir. Elektrik enerjisinin depolanması zor ve maliyetlidir. Bu nedenle elektrik üretim ve tüketimindeki arz talep dengesinin sağlanması oldukça önemlidir. Üretilen elektriğin talepten az olması enerjide dişa bağımlılığa sebep olacağ1 gibi, fazla olması ise ekonomik olarak değerlendirilemeyecek yatırımların oluşmasına neden olacaktır. Bu zorluğun üstesinden gelebilmek için ülkelerin makul seviyede elektrik enerjisi üretim planları yapabilmesi ve enerji talebine ilişkin planlama stratejileri geliştirebilmesi gereklidir. Elektrik enerjisinin tüketiminde nüfus değişimleri, coğrafi faktörler, sanayileşme, ülkeler arası ithalat ve ihracat değişimleri, iklimsel sıcaklık değişimleri, atmosferik değişimler ve sezona bağlı yük değişimleri gibi birçok faktör etkili olmaktadır. Bu faktörler tahmin stratejisinin belirlenmesinde ülkenin veya bir bölgenin elektrik talebinin oluşmasındaki belirleyici parametreler ile ilişkilendirilmelidir.

Elektrik talep tahmini birçok araştırmacı tarafından incelenmiş ve farklı tahmin stratejileri geliştirilmiştir. Gerileme yöntemini kullanarak Gaziantep yöresi için beş yıllık yük tahmin analizi gerçekleştirilmiştir (Hermingen ve Kabak, 1999). Gölbaşı Bölgesi'ne ait gerçek güç verileri kullanılarak, geriye yayılım algoritması ile eğitilen çok katmanlı YSA modeli ile bir sonraki günün 24 saatlik yük tahmini yapılmıştır (Ceylan, 2004). Türkiye'de enerji tüketimini belirlemek için YSA tekniği kullanılarak Net Enerji Tüketim tahmini incelenmiş ve ağ eğitimi için farklı topolojiler sunulmuştur (Sözen ve ark., 2005). Türkiye' nin enerji tüketimini tahmin etmek için ithalat, ihracat nüfus artışı ve ekonomik göstergelere dayanan üç farklı model kullanılarak YSA yardımı ile tüketim tahmini yapılmıştır (Sözen ve Arcaklığlu, 2007). Doğrusal regresyon modeli kullanılarak İtalya' da 1970-2007 yılları arasındaki elektrik tüketimi, ekonomik ve nüfus değişkenlerin etkisi kullanılarak incelenmiş ve uzun süreli tüketim tahmini değerlendirilmiştir (Bianco ve ark., 2009). 1970-2007 yılları arası Gayri Safi Milli Hâsıla, üretilen enerji, tüketilen enerji, nüfus ve kurulu güç verilerini kullanılak, adaptif ağ tabanlı bulanık çıkarım sistemi ve otoregresif hareketli ortalamalar yardımıyla elektrik enerji tahminini incelemiş ve 2006-2010 yılları arası elektrik enerjisi talep tahminleri için farklı iki model karşılaş̧ırılmıştır (Demirel ve ark., 2009). Türkiye'de 2010-2025 yılları arasındaki günlük puant zamanında tüketilen enerji ve tüketilen toplam enerji miktarı tahmin edilmiştir (Oğurlu, 2011). Türkiye'deki 2003-2010 yılları arası saatlik enerji tüketim verileri kullanılarak, 2004-2010 yılları arasında günlük yük tahmi regresyon analizi olan en küçük kareler yöntemi ile gerçekleştirilmiş ve tahmin sonuçları gerçek değerlere bağlı olarak değerlendirilmiştir (Balcı ve ark., 2012). Türkiye'nin kısa dönem elektrik talebi tahmini için bir bulanık mantık modeli oluşturulmuş ve bu model zaman serisi ve regresyon analizi ile elde edilen modeller ile karşılaştırılmıştır (Yavuzdemir, 2014). Kurulu güç, bürüt elektrik üretimi, nüfus ve toplam abone sayılarına ait veriler kullanılarak çoklu regresyon analizi, yapay sinir ağları (YSA) ve en küçük kareler destek vektör makineleri metotları yardımıyla Türkiye' de uzun dönem elektrik üretim tahmini gerçekleştirilmiştir (Kaytez ve ark., 2015). 1970-2009 yılları arasında Türkiye' nin elektrik enerji tüketimi, En Küçük Kareler - Destek Vektör Makinesi (LSSVM), YSA ve Regresyon analizi yöntemleri kullanılarak tahmin edilmiştir (Çevik ve Çunkaş, 2015). Küçük bir bölgenin yük tahmini için YSA ve regresyon analizlerini içeren hibrit bir sistem önerilmiştir (Hocaoğlu ve ark., 2015). Seydişehir bölgesinin 1995-2014 yılları arası nüfus, sıcaklık, nem, rüzgâr ve enerji tüketim verileri kullanılarak, YSA ve ANFIS yöntemleri ile 2014-2016 yılları arası aylık ve yıllık bazlarda enerji talep tahmini incelemiştir (Sönmez, 2015). Yapay arı kolonisi ve YSA kombinasyonuna dayalı hibrit bir yöntem kullanılarak, Türkiye' de kısa dönem yük tahmini için farklı bir yaklaşım sunmuştur (Çevik ve ark., 2016). Çoklu regresyon yaklaşımı kullanılarak elektrik tüketim talebini etkileyen faktörler için bir değerlendirme sunmuştur (Karaca ve Karacan, 2016). Yine benzer şekilde elektrik tüketim tahmini için farklı YSA modelleri ve genetik algoritma gibi yaklaşımlar elektrik tüketim tahmininde kullanılmıştır (Pençe ve ark., 2016; Ekinci, 2019; Özger ve ark., 2019; Basheer ve Hajmeer, 2000).

Bu çalışmada, Türkiye'nin 1985-2019 yılları arasındaki kurulu güç kapasitesi, bürüt elektrik üretimi, net elektrik tüketimi, ithalat, ihracat ve nüfus gibi enerji göstergeleri kullanılarak Türkiye'de petrolden, gazdan, kömürden ve diğer (yenilenebilir enerji) kaynaklardan elektrik üretiminin tahmini için yapay sinir ağı tabanlı tahmin metodolojisi sunulmuştur. Tahmin sonuçları ile gerçekleşen projeksiyon değerleri karşılaştırılarak istatistiksel olarak değerlendirilmiştir. 


\section{YAPAY SINIIR AĞI (YSA)}

YSA karmaşık problemleri çözmek amacıyla, insan beyindeki sinir hücrelerinin yapay olarak taklit edilerek bilgisayar sistemlerine uygulanması prensibine dayalı bir veri işleme tekniğidir. YSA kendisine verilen örnekleri kullanarak öğrenme işlemini gerçekleştirir (Basheer ve Hajmeer, 2000; Graupe, 2007).

YSA'nın temel yapı birimini oluşturan yapay sinir hücrelerinin (nöronların) genel yapısı; girdiler (xi), ağırlıklar (wi), aktivasyon (transfer) fonksiyonu ve çıtıllar olmak üzere beş ana kısımdan oluşmaktadır. Girdilerin her biri ağırlık ile çarpılarak elde edilen ürünler basitçe eşik değeri ile toplanır ve sonucu oluşturmak için aktivasyon fonksiyonu ile işlem yapılır ve çıkışı alınır. Bir yapay sinir hücresinin öğrenme yeteneği, seçilen öğrenme algoritması içerisinde ağırlıkların uygun bir şekilde ayarlanmasına bağlıdır (Cho, 2003).

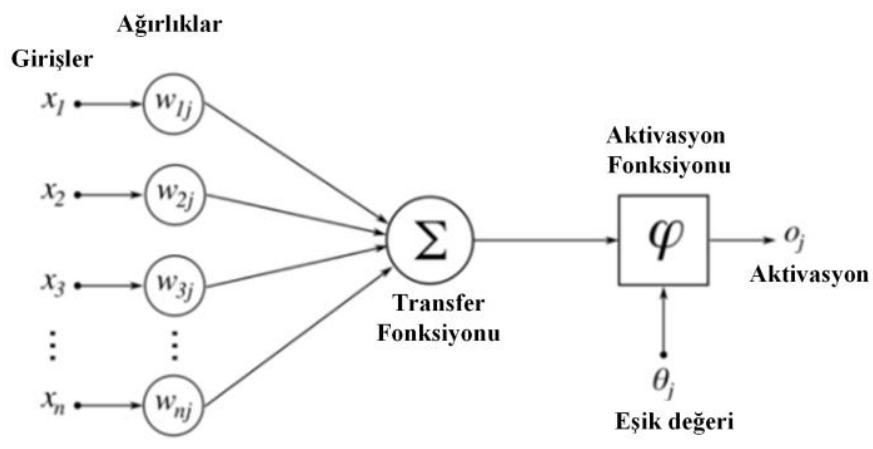

Şekil 1. Temel YSA blok yapısı.

\section{ELEKTRIKK ÜRETIM TAHMINNDE YSA KULLANIMI}

Enerji üretimi ile enerji göstergeleri arasında güçlü bir bağlantı söz konusudur. $\mathrm{Bu}$ açıdan değerlendirildiğinde, Türkiye'deki kurulu güç kapasitesi, net elektrik tüketimi, brüt elektrik üretimi, ülkenin ithalat ve ihracat verileri ve nüfus değişimi gibi göstergeler enerji üretim ve tüketimi tahmininde belirleyici parametreler olarak kullanılabilir. Bu çalışmada belirtilen bu enerji göstergeleri ağ giriş parametreleri olarak yapay sinir ağı eğitiminde kullanılmıştır. Enerji göstergelerinin Türkiye'de 1975-2019 yılları arasındaki değişimleri grafiksel olarak Şekil 2'de sunulmuştur (Ercan ve ark., 2020; BP Dünya Enerjisinin İstatistiksel Değerlendirmesi, 2020)

YSA analizleri MATLAB kullanılarak gerçekleştirilmiştir. YSA modellenmesinde ileri yönlü çok katmanlı algılayıcı (IYÇKA) ağ topolojisi kullanılmıştır. Model yapısında giriş değişkenleri olarak Şekil 2'de gösterildiği gibi enerji göstergelerini içeren altı zaman değişkeni seçilmiştir. Çıkış değişkenleri ise petrolden, kömürden, gazdan ve diğer enerji kaynaklarından (yenilenebilir enerji) elektrik üretimi olmak üzere dört çıkış parametresi olarak tanımlanmıştır.

YSA modelinde nöronların uygun transfer fonksiyonu denklem 1'deki gibi lojistik sigmoid fonksiyon $f\left(z_{i}\right)$ olarak ifade edilmiştir. İkinci denklemde tanımlanan $z_{i}$ ifadesi ise girişlerin toplam ağırlığını ifade etmekedir. $x_{j}$ ifadesi j. nörondan direk olarak gelen sinyaldir. $w_{i j} j$. nörondan i. nörona direk olarak bağlanan ağırlıkları tanımlamaktadır. Çalışmada sunulan 6 giriş, 4 çıkış ve 10 gizli katman içeren ileri yönlü çok katmanlı algılayıcı (IYÇKA) ağ topolojisi şekil 3'de gösterilmiştir. 


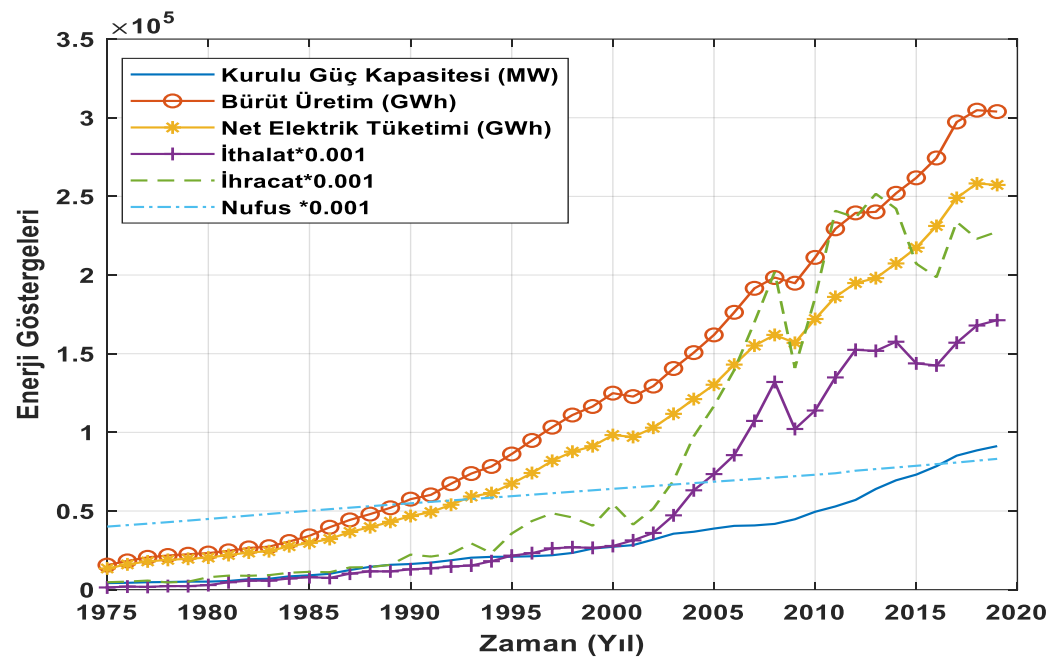

Şekil 2. Türkiye'de enerji göstegeleri.

$$
\begin{aligned}
& f\left(z_{i}\right)=\frac{1}{1+e^{-z_{i}}} \\
& z_{i}=\sum_{j=1}^{10} w_{i, j} x_{j}+\beta_{i}
\end{aligned}
$$

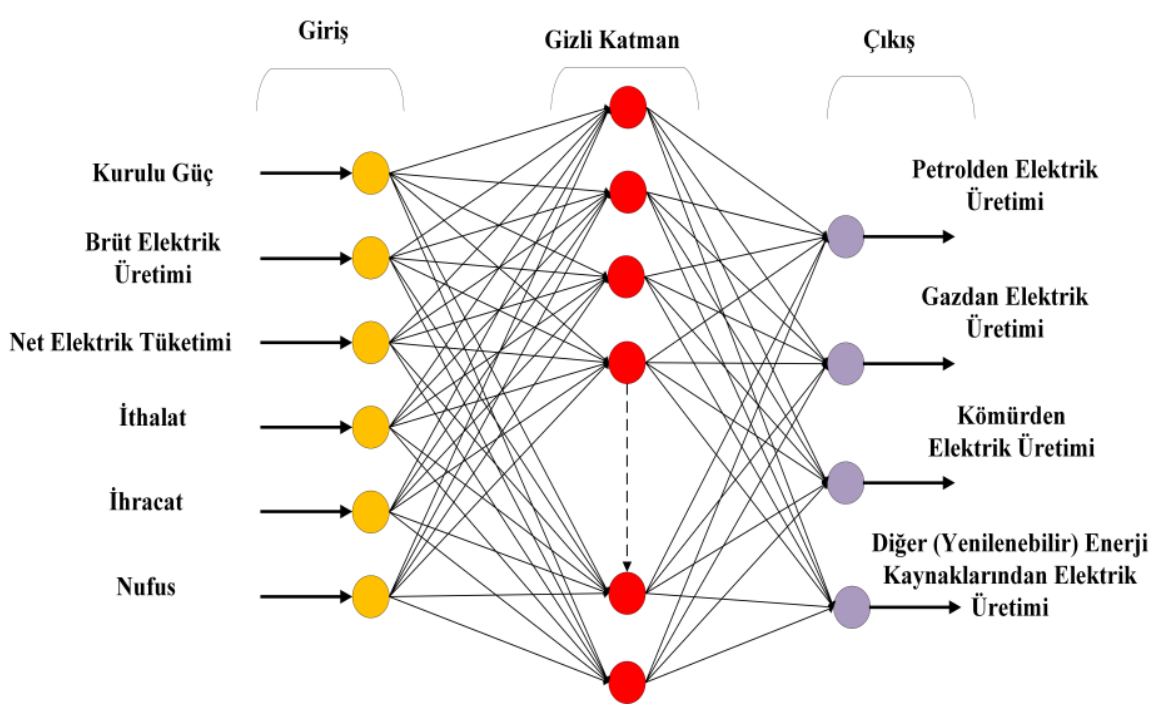

\section{Şekil 3.Enerji üretim tahmininde kullanılan ileri yönlü çok katmanlı algılayıcı (IYÇKA) ağ topolojisi.}

\section{DENEYSEL SONUÇLAR}

Bu çalışmada, Şekil 3'de sunulan giriş parametreleri kullanılarak: YSA yardımı ile petrolden, gazdan, kömürden ve yenilenebilir enerji kaynakları gibi diğer enerji kaynaklarından elektrik üretim tahmini gerçekleştirilmiştir. Levenberg-Marquardt (LM) geri yayılımı kullanılarak giriş verileri eğitilmiştir. Analizde 1985-2019 yılları arasındaki veri setleri kullanılmış ve 2015-2019 yıllarındaki veri seti değerleri sunulan yaklaşımın doğruluğunu belirlemede test verisi olarak seçilmiştir. Sonuçlar istatistiksel olarak değerlendirilmiştir. 
YSA analizi sonucunda ağ eğitim durumu, doğrulama performansı ve regresyon analiz değerler sirası ile Şekil4, Şekil 5 ve Şekil 6'da gösterilmiştir. Test verisi olarak kullanılan 2015-2019 yılları aralığındaki gerçek değerler ve tahmin değerleri ise Tablo 1'de sunulmuştur.

İstatistiksel değerlendirme için Tahmin edilen ve ölçülen değerlerin yorumlanmasında Ortalama Karesel Hata $(\mathrm{OKH})$, Ortama Mutlak Hata $(\mathrm{OMH})$ ve Kare Ortalama Karesel Hata $(\mathrm{KOKH})$ değerleri hesaplanmıştır denklem (3-5)'e göre hesaplanmıştır. Hesaplama sonuçları Tablo 2' de gösterilmiştir.

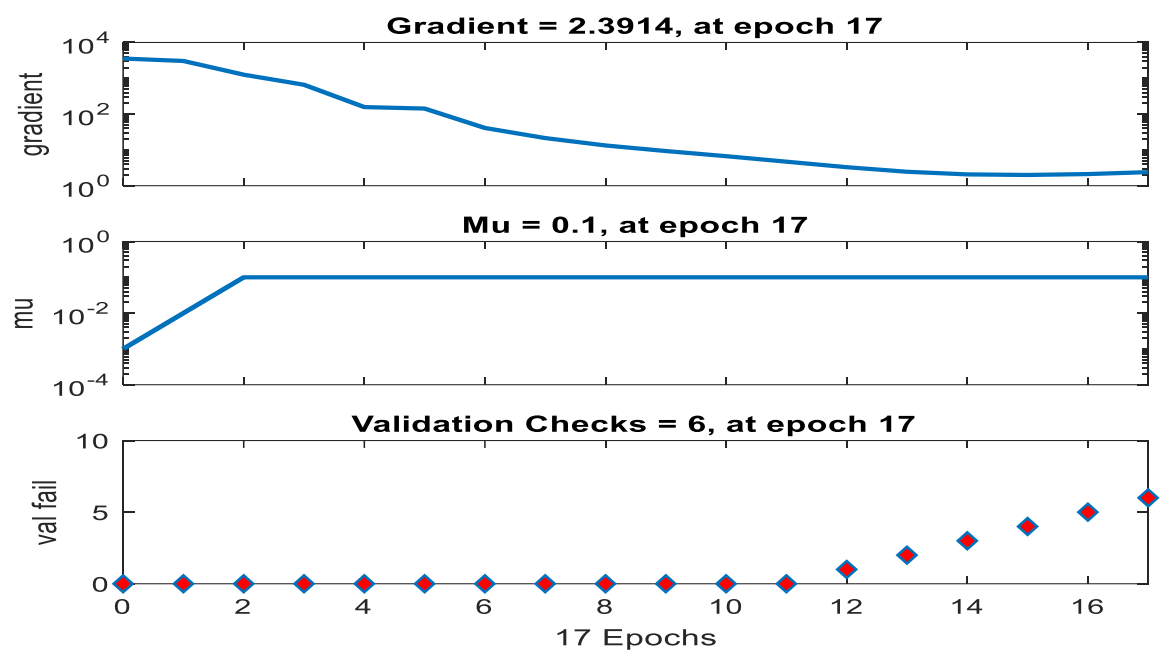

Şekil 4. YSA eğitim durumu

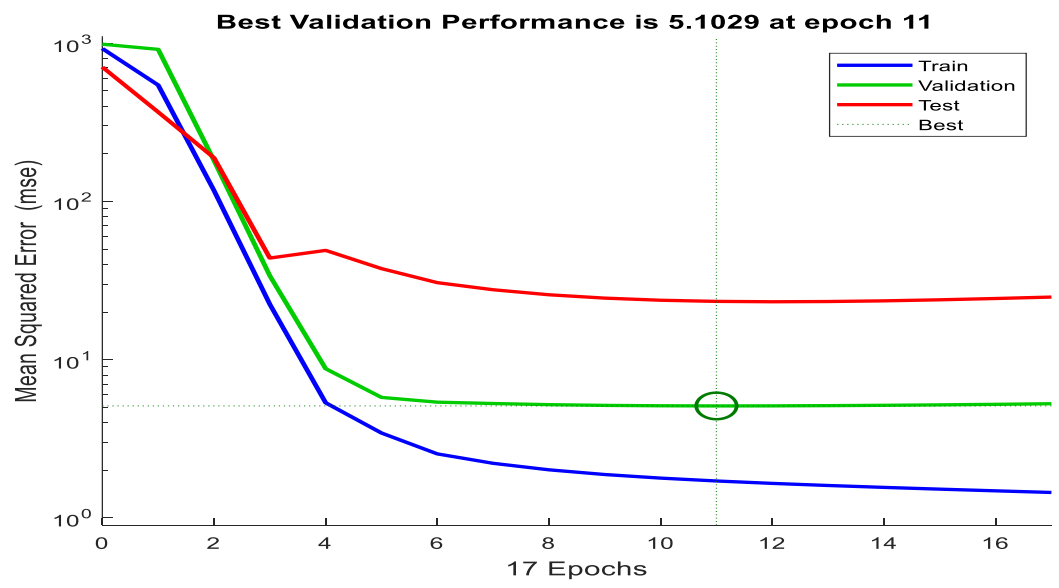

Şekil 5. YSA doğrulama performansı 

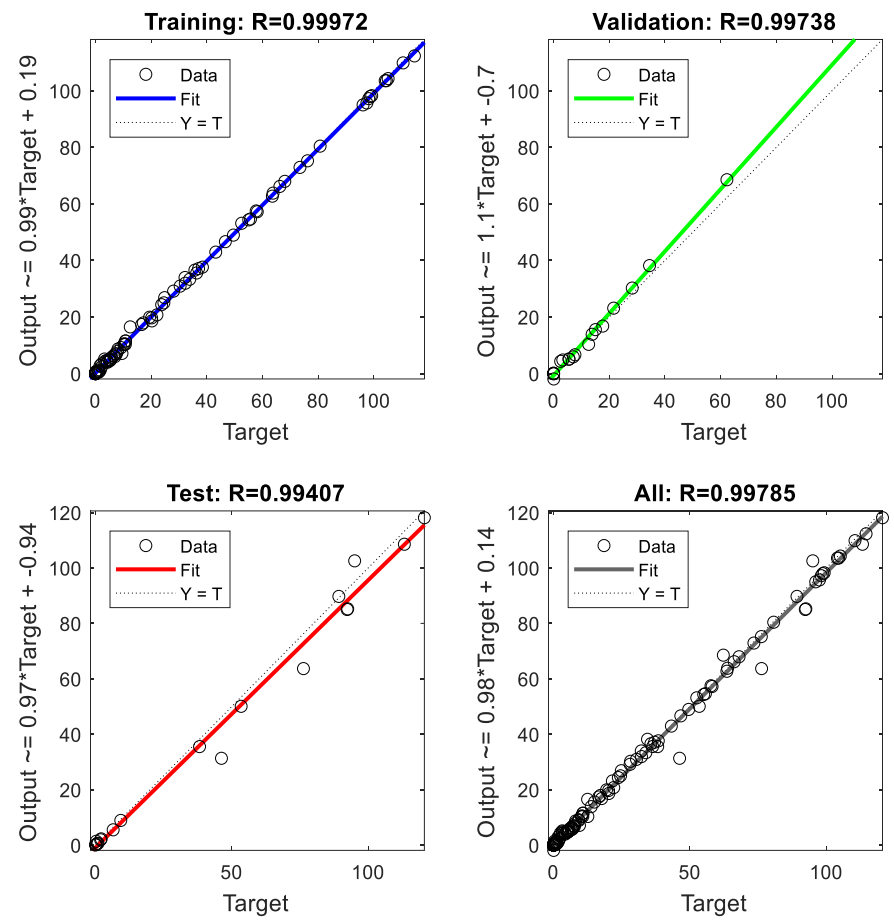

Şekil 6. YSA sonucunda elde edilen çıkış tahminleri ile üretim değerlerinin regresyon analizi.
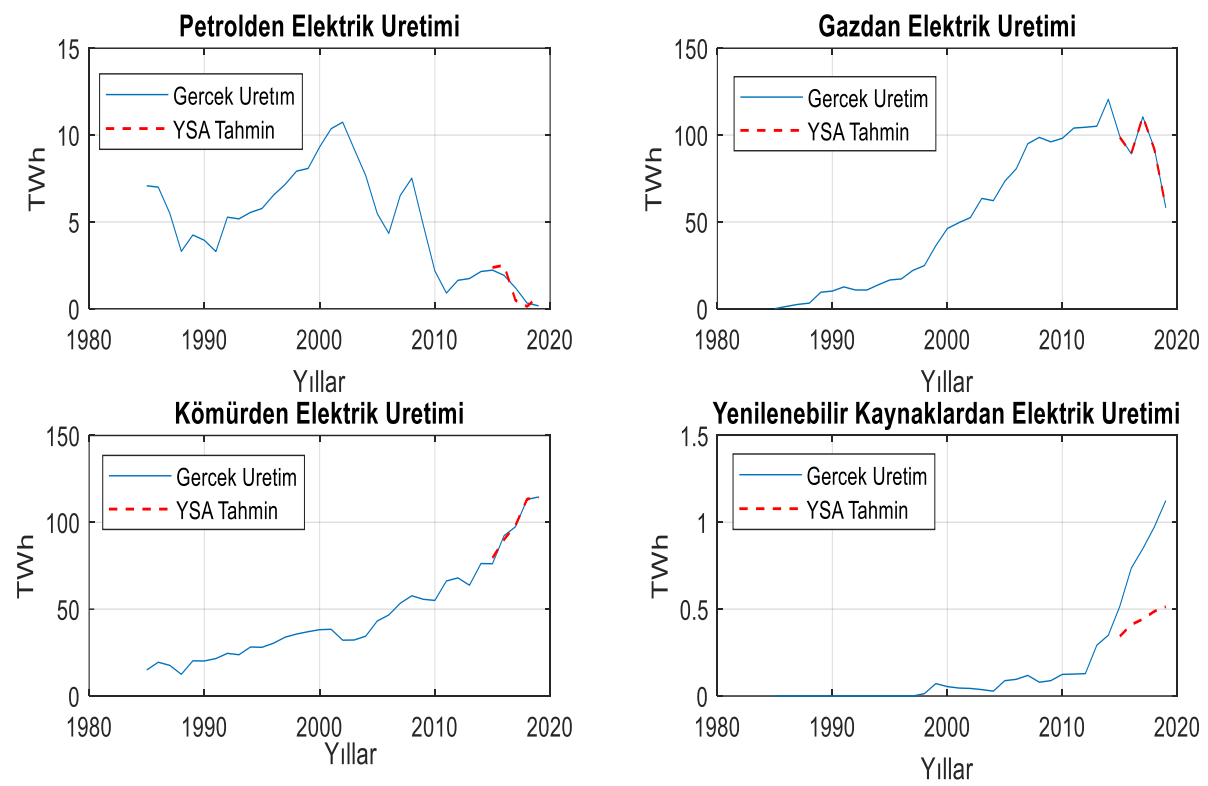

Şekil 7.Farklı üretim yöntemleri ile gerçek tüketim değerleri ve YSA tahmini ile elde edilen elektrik üretim değerlerinin karşılaştırılması.

Tablo 1. Gerçek elektrik üretim ve YSA tahmin verileri.

\begin{tabular}{|l|c|c|c|c|c|c|}
\hline \multicolumn{1}{|c|}{ Üretim Türü } & Yıllar & $\mathbf{2 0 1 5}$ & $\mathbf{2 0 1 6}$ & $\mathbf{2 0 1 7}$ & $\mathbf{2 0 1 8}$ & $\mathbf{2 0 1 9}$ \\
\hline \multirow{2}{*}{ Petrolden Elektrik Üretimi } & Üretim verisi & 2.224 & 1.926 & 1.199 & 0.329 & 0.169 \\
\cline { 2 - 7 } & YSA tahmini & 2.374 & 2.506 & 0.480 & 0.136 & 0.721 \\
\hline \multirow{2}{*}{ Gazdan Elektrik Üretimi } & Üretim verisi & 99.218 & 89.227 & 110.49 & 92.482 & 58.117 \\
\cline { 2 - 7 } & YSA tahmini & 98.639 & 89.548 & 110.686 & 91.842 & 58.505 \\
\hline \multirow{2}{*}{ Kömürden Elektrik Üretimi } & Üretim verisi & 76.166 & 92.273 & 97.476 & 113.249 & 114.563 \\
\cline { 2 - 7 } & YSA tahmini & 79.529 & 90.033 & 98.368 & 113.389 & 114.434 \\
\hline \multirow{2}{*}{$\begin{array}{l}\text { Diğer (Yenilenebilir Enerji) } \\
\text { Kaynaklarından Elektrik Üretimi }\end{array}$} & Üretim verisi & 0.517 & 0.737 & 0.848 & 0.973 & 1.125 \\
\cline { 2 - 7 } & YSA tahmini & 0.344 & 0.411 & 0.443 & 0.487 & 0.514 \\
\hline
\end{tabular}


Tablo 2. Enerji üretim tahminin için hesaplanan istatistiksel değerler.

\begin{tabular}{lccc}
\hline & OKH & OMH & KOKH \\
\hline Petrolden Elektrik Üretimi & 0.244 & 0.975 & 0.494 \\
Gazdan Elektrik Üretimi & 0.207 & 0.005 & 0.455 \\
Kömürden Elektrik Üretimi & 3.432 & 0.016 & 1.853 \\
Diğer (Yenilenebilir Enerji) & 0.182 & 0.879 & 0.427 \\
Kaynaklarından Elektrik üretimi & & \\
\hline
\end{tabular}

$$
\begin{aligned}
& O K H=\left[\frac{1}{N} \cdot \sum(O ̈ l c ̧ u ̈ m \text { de ğeri }- \text { Tahmin de ğeri })^{2}\right] \\
& O M H=\left[\frac{1}{N} \sum \frac{\text { Ölçüm değeri }- \text { Tahmin değeri }}{\text { Tahmin değeri }}\right]
\end{aligned}
$$

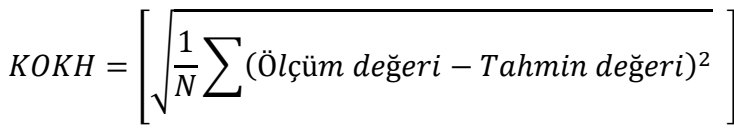

\section{SONUÇLAR}

Bu çalışma ile, Türkiye'nin 1985-2019 yılları arasındaki kurulu güç kapasitesi, bürüt elektrik üretimi, net elektrik tüketimi, ithalat, ihracat ve nüfus gibi enerji göstergeleri kullanılarak enerji üretim tahmini için yapay sinir ağı (YSA) tabanlı tahmin metodolojisi sunulmaktadır. Analizde YSA modeli 6 giriş, 4 çıkış ve 10 gizli katman içeren ileri yönlü çok katmanlı algılayıcı (IYÇKA) ağ topolojisi olarak tasarlanmıştır. Enerji göstergeleri YSA modelinin giriş parametresi olarak seçilmiş ve çıkış parametresi olarak Türkiye'de kömürden, gazdan, petrolden ve yenilenebilir enerji kaynaklarından enerji tahmini tanımlanmıştır. Elde edilen sonuçlar incelendiğinde sunulan yaklaşımın yüksek doğrulukta enerji üretim tahminin karşıladığı görülmektedir. Yenilebilir enerji için YSA eğitimi istenilen performansa sahip değildir. Bunun nedeni yenilebilir enerji kaynaklarının son yıllarda popüler olması ve YSA eğitimi için yeterli örnek sayısına sahip olmamasından kaynaklanmaktadır.

Gelecekte bu çalışma geliştirilerek derin öğrenme algoritmaları yardımıyla tahmin doğruluğunun arttırılması amaçlanmaktadır.

\section{REFERANSLAR}

Basheer I.A, Hajmeer M. (2000) Artificial neural networks: fundamentals, computing, design, and Application, Journal of Microbiological Methods, 43: 3-31.

Balcı H, Esener Işıklı İ, Kurban M. (2012) Regresyon Analizi Kullanılarak Kısa Dönem Yük Tahmini ELECO'2012 Elektrik - Elektronik ve Bilgisayar Mühendisliği Sempozyumu, Bursa.

Bianco V, Manca O, Nardini S. (2009) Electricity consumption forecasting in Italy using linear regression models, Energy ,34 (9), 1413-1421.

BP Dünya Enerjisinin İstatistiksel Değerlendirmesi Haziran, 2020.

Ceylan G. (2004) Yapay sinir ağları ile kısa dönem yük tahmini, Yüksek Lisans Tezi, İstanbul Teknik Üniversitesi, Fen Bilimleri Enstitüsü, İstanbul.

Cho V.A. (2003) Comparison of three different approaches to tourist arrival forecasting, Tourism Management, 24: 323-330.

Çevik H, Çunkaş M. (2015) Short-term load forecasting using fuzzy logic and ANFIS, Neural Comput \& Applic, 26 (6), 1355-1367. 
Çevik H.H, Harmancı H, Çunkaş M. (2016) Short-term Load Forecasting based on ABC and ANN for Smart Grids, IJISAE, 2016, 4(Special Issue).

Demirel Ö, Kakilli A, Tektaş M. (2009) ANFIS ve ARMA modelleri ile elektrik enerjisi yük tahmini, Gazi Üniversitesi Gazi Üniv. Müh. Mim. Fak. Der, Cilt 25, No 3, 601-610.

Ekinci F. (2019) YSA VE ANFIS Tekniklerine Dayalı Enerji Tüketim Tahmin Yöntemlerinin Karş1laştırılması, Düzce Üniversitesi Bilim ve Teknoloji Dergisi.

Ercan U, Irmak S, Çevik K.K, Canbazoğlu E. (2020) Yapay Sinir Ağları Kullanılarak Konutlarda Elektrik Tüketimi Düzeylerinin Tahmin Edilmesi, Sosyoekonomi, Vol. 28(46), 173-186.

Graupe D. (2007) Principles of artificial neural networks, (2nd Edition), advanced series on circuits and systems, 6, World Scientific Publishing Co. Pte. Ltd.

Hengirmen M.O, Kabak S. (1999) Gaziantep ve Yöresinde 5 Yıllık Elektrik Enerjisi İhtiyaç Tahminleri, Elektrik Elektronik Bilgisayar Mühendisliği 8. Ulusal Kongresi, Gaziantep.

Hocaoğlu F.O, Kaysal K, Kaysal A. (2015) Yük Tahmini İçin Hibrit (YSA ve Regresyon) Model, Afyon Kocatepe Üniversitesi, Mühendislik Fakültesi, Afyonkarahisar.

Karaca C, ve Karacan H. (2016) Çoklu Regresyon Metoduyla Elektrik Tüketim Talebini Etkileyen Faktörlerin İncelenmesi, Selçuk Üniversitesi Mühendislik Fakültesi.

Kaytez F, Taplamacioğlu M.C, Çam E, Hardalaç F. (2015) Forecasting electricity consumption: A comparison of regression analysis, neural networks and least squares support vector machines, Electrical Power and Energy Systems, 67, 431-438.

Oğurlu H. (2011) Matematiksel Modelleme Kullanarak Türkiye'nin Uzun Dönem Elektrik Yük Tahmini, Yüksek Lisans Tezi, Selçuk Üniversitesi Fen Bilimleri Enstitüsü, Konya.

Özger Y.E, Akpınar M, Musayev Z, Yaz M. (2019) Elektrik Yükünün Genetik Algoritma Temelli HoltWinters Üstel Düzeltme Yöntemiyle Tahmini, SAKARYA Unıversıty Journal Of Computer And Information Sciences.

Pençe İ, Kalkan A, Çeşmeli Ş.M. (2017) Türkiye Sanayi Elektrik Enerjisi Tüketiminin 2017-2023 dönemi için Yapay Sinir Ağları ile Tahmini, Mehmet Akif Ersoy Üniversitesi Uygulamalı Bilimler Dergisi.

Sönmez İ. (2015) Seydişehir Bölgesinin Orta Vadedeki Elektrik Enerjisi Talebinin Yapay Zekâ ile Tahmini Yüksek Lisans Tezi, Selçuk Üniversitesi Fen Bilimleri Enstitüsü, Konya.

Sözen A, Arcaklığlu E. (2005) Özkaymak M., Turkey’s net energy consumption, Applied Energy.

Sözen A, Arcaklığlu E. (2007) Prediction of energy consumption based on economic indicators (GNP and GDP) in Turkey, Energy Policy, Volume 35, Issue 10, Pages 4981-4992.

Yavuzdemir M. (2014) Türkiye'nin Kısa Dönem Y1llık Brüt Elektrik Enerjisi Talep Tahmini, Yüksek Lisans tezi, Ankara Üniversitesi Sosyal Bilimler Enstitüsü, Ankara. 